\title{
INVESTIGATION OF P-CHLOROANILINE FORMATION IN THE REACTIONS BETWEEN DIFFERENT ENDODONTIC IRRIGANTS
}

\author{
Ljiljana Z. Bjelovića ${ }^{a}$ Biljana Đ. Glišićc , Marija D. Živkovićc and Tatjana V. Kanjevac ${ }^{\mathrm{d}}$ \\ ${ }^{a}$ University of East Sarajevo, Faculty of Medicine, Department of Restorative Dentistry and \\ Endodontics, Studentska bb, Foča 73 300, Bosnia and Herzegovina; \\ ${ }^{b}$ University of Kragujevac, Faculty of Science, Department of Chemistry, \\ R. Domanovića 12, Kragujevac 34000, Serbia; \\ ${ }^{c}$ University of Kragujevac, Faculty of Medical Sciences, Department of Pharmacy, \\ Svetozara Markovića 69, 34000 Kragujevac, Serbia \\ ${ }^{d}$ University of Kragujevac, Faculty of Medical Sciences, Department of Dentistry, \\ Svetozara Markovića 69, 34000 Kragujevac, Serbia \\ *Corresponding author; E-mail: tatjanakanjevac@yahoo.com
}

(Received October 5th, 2018; Accepted December 10th, 2018)

\begin{abstract}
The aim of this study was to determine whether $p$-chloroaniline (PCA) is formed in the reactions of sodium hypochlorite $(\mathrm{NaOCl})$ with final rinse chlorhexidine (CHX), QMix (combination of ethylenediaminetetraacetic acid (EDTA), CHX and detergent) and EDTA/CHX solutions by thin-layer chromatography (TLC), proton nuclear magnetic resonance $\left({ }^{1} \mathrm{H}\right.$ NMR) and infrared (IR) spectroscopy. Commercially available $5.25 \% \mathrm{NaOCl}$ solution was mixed with $2 \% \mathrm{CHX}$ and QMix in 1:1 (v/v) ratio at room temperature. Furthermore, $2 \% \mathrm{CHX}$ was associated with $17 \%$ EDTA under the same experimental conditions. The obtained solutions were evaluated qualitatively for color changing, precipitate and/or bubble formation and analyzed by TLC chromatography. The association products were investigated by spectroscopic $\left({ }^{1} \mathrm{H}\right.$ NMR and IR) methods in order to determine whether they contain PCA. It was found that interactions between $\mathrm{NaOCl} / \mathrm{CHX}$ and $\mathrm{CHX} / \mathrm{EDTA}$ led to forming of brown and white precipitate. When $\mathrm{NaOCl}$ was mixed with QMix, an orange-brown precipitate was formed. PCA was not detected as a product of the reactions between $\mathrm{NaOCl}$ and final rinse solutions of CHX, QMix and EDTA/CHX association.
\end{abstract}

Key words: $p$-Chloroaniline, Infrared spectroscopy, Irrigants, Proton nuclear magnetic resonance, Thin-layer chromatography

\section{INTRODUCTION}

Root canal irrigation, mechanical or chemical, aims to remove debris, lubricate the canal, dissolve organic and inorganic tissues, as well as to prevent smear layer formation or aid its removal (ZEHNDER et al., 2005; HÜLSMANN et al., 2007; HAAPASALO et al., 2014). The biological function of the irrigants is related to their antimicrobial effect, inactivation of 
endotoxin, non-toxicity to vital tissues and low allergenic potential (ZEHNDER et al., 2005). The most commonly used irrigants in endodontic therapy are sodium hypochlorite $(\mathrm{NaOCl})$, ethylenediaminetetraacetic acid (EDTA) and chlorhexidine (CHX) (ZEHNDER et al., 2005; HÜLSMANN et al., 2007; GU et al., 2009; BITTER et al., 2013; HAAPASAlO et al., 2014). In order to reduce surface tension of irrigants, improve their dentinal tubules penetration and enhance their efficiency, combination of two or more irrigants is recommended (STOJICIC et al., 2010). Accordingly, QMix (combination of EDTA, CHX and detergent; Dentsply TulsaDental, Tulsa, OK, USA) have been introduced in endodontic practice (STOJICIC et al. 2012). Previous studies showed that QMix is as effective as 17\% EDTA in removal of smear layer or even superior (DAI et al., 2011; STOJICIC et al., 2012). Moreover, QMix is as efficacious antimicrobial agent as $6 \% \mathrm{NaOCl}$ and superior when compared to CHX, MTAD (mixture of doxycycline, citric acid and detergent) and solutions of $\mathrm{NaOCl}$ with lower concentrations (DAI et al., 2011; WANG et al., 2012).

Numerous in vitro studies showed that chemical interactions between some irrigants result in formation of precipitates (TAY et al., 2006; BASRANI et al., 2007; RASIMICK et al., 2008; ARSLAN et al., 2015). Clinical relevance of the precipitate is in its difficult removal from the canal which can contribute to periapical $p$-chloroaniline (PCA) leaching (VIVAQUAGOMES et al., 2002). Some of these studies (BASRANI et al., 2007; BASRANI et al., 2010) demonstrated that successive rinsing of root canal with $\mathrm{NaOCl}$ and $\mathrm{CHX}$ produced an orangebrown precipitate, which contains PCA. However, these findings were not confirmed in the other studies (THOMAS et al., 2010; ORHAN et al., 2016). It is worth noting that PCA is carcinogenic and toxic (CHHABRA et al., 1991; KACMAR et al., 1995) and can lead to dentin discoloration (SoUZA et al., 2013). After mixing CHX and EDTA, non-toxic white precipitate formation was noticed (RASIMICK et al., 2008). There are only a few studies related to precipitate formation in the interactions of most commonly used irrigant $\mathrm{NaOCl}$ with QMix solution (ARSLAN et al., 2015; KOLOSOWSKI et al., 2014), in which PCA was not detected.

A recent study of ORHAN et al., 2016 has showed that different methods can be used for PCA presence analysis in the precipitate resulted from $\mathrm{NaOCl} / \mathrm{CHX}$ association. Additionally, THOMAS et al., 2010 reported that mass spectrometry is not a reliable method for PCA formation detection, as well as Beilstein and $\mathrm{HCl}$ solubility tests (KRISBNAMURTBY et al., 2010). Therefore, the aim of this study was to determine whether PCA is formed in the reactions of $\mathrm{NaOCl}$ with final rinse $\mathrm{CHX}$ and QMix solutions, as well as a result of EDTA/CHX combination by thin-layer chromatography (TLC), proton nuclear magnetic resonance $\left({ }^{1} \mathrm{H}\right.$ NMR) and infrared (IR) spectroscopy.

\section{MATERIALS AND METHODS}

\section{Chemicals}

Commercially available solutions (5.25\% NaOCl, 2\% CHX (Consepsis, Dentsply Tulsa Dental, Tulsa, OK, USA), 17\% EDTA (ENDO-SOLution, Cerkamed, PPH Cerkamed, Stalowa Wola, Poland) and QMix) were used in the study. PCA, ethyl acetate, hexane, sodium sulfate and deuterated dimethyl sulfoxide (DMSO- $d_{6}$ ) were purchased from the Sigma-Aldrich (St. Louis, Missouri, USA). All the employed chemicals were of analytical reagent grade and used without further purification.

\section{Associations}

$5 \mathrm{~mL}$ of $5.25 \% \mathrm{NaOCl}$ solution was mixed with $5 \mathrm{~mL}$ of $2 \% \mathrm{CHX}$ and QMix at room temperature. In addition, 2\% CHX was associated with 17\% EDTA in 1:1 (v/v) ratio. The 
final solutions were evaluated qualitatively for color changing, precipitate and/or bubble formation. The visual characteristics of the irrigants' resultant association were summarized in Table 1.

Table 1. Visual characteristics of the irrigants association observed in this study.

\begin{tabular}{lll}
\hline Solution 1 & Solution 2 & Visual characteristic of the association* \\
\hline $5.25 \% \mathrm{NaOCl}$ & $2 \% \mathrm{CHX}$ & Brown precipitate \\
$5.25 \% \mathrm{NaOCl}$ & QMix & Orange-brown coloring and bubble formation \\
$2 \% \mathrm{CHX}$ & $17 \% \mathrm{EDTA}$ & White cloudy precipitate \\
\hline
\end{tabular}

*Solutions were mixed in 1:1 (v/v) ratio at room temperature.

\section{PCA Formation analysis}

After mixing $5.25 \% \mathrm{NaOCl}$ with $2 \% \mathrm{CHX}$, a brown-colored mixture was extracted three times with $15.0 \mathrm{~mL}$ ethyl acetate, and then organic layer was separated and dried over anhydrous sodium sulfate (ORHAN et al., 2016). This solution was analyzed by TLC and then ethyl acetate was removed under reduced pressure. The isolated brown precipitate was further evaluated by spectroscopic ( ${ }^{1} \mathrm{H}$ NMR and IR) methods in order to determine whether it contains PCA.

In the case of the other two irrigants associations, the resulting solution was analyzed by TLC and then solvent was removed under reduced pressure. The obtained solids (white for $2 \% \mathrm{CHX} / 17 \%$ EDTA and orange-brown for 5.25\% NaOCl/QMix) were further analyzed by spectroscopic $\left({ }^{1} \mathrm{H}\right.$ NMR and IR) methods.

Silica gel 60 on Al plates with layer thickness $0.2 \mathrm{~mm}$ (Merck) was used for TLC. Two drops of the corresponding solution were injected on TLC plate. Near this spot, two drops of solution obtained by dissolving $2.0 \mathrm{mg}$ of PCA in $1.0 \mathrm{~mL}$ of ethyl acetate were injected as stationary phase. This plate was placed in a TLC tank containing ethyl acetate/hexane mixture in 1:2(v/v) ratio as mobile phase. ${ }^{1} \mathrm{H}$ NMR spectra were recorded at $25{ }^{\circ} \mathrm{C}$ on a Varian Gemini 2000 spectrometer at $200 \mathrm{MHz}$. $20.0 \mathrm{mg}$ of PCA and the corresponding association products were dissolved in $0.7 \mathrm{~mL}$ of DMSO- $d_{6}$ and transferred into a $5 \mathrm{~mm}$ NMR tube. Chemical shifts are reported in ppm $(\delta)$ and scalar couplings are reported in Hertz. IR spectra were recorded as $\mathrm{KBr}$ pallets on a Perkin Elmer Spectrum One spectrometer over the range $4000-450 \mathrm{~cm}^{-1}$.

\section{RESULTS AND DISCUSSION}

The visual irrigants' resultant association characteristics are summarized in Table 1. Brown and white precipitates were formed in the interactions of $2 \% \mathrm{CHX}$ with $5.25 \% \mathrm{NaOCl}$ and $17 \%$ EDTA, respectively, immediately after mixing of these irrigants, while the combination of $5.25 \% \mathrm{NaOCl}$ with QMix resulted in orange-brown solution coloration and bubbles formation.

Different irrigating solutions combinations were studied for PCA presence by TLC, ${ }^{1} \mathrm{H}$ NMR and IR measurements. The corresponding data for each combination were compared with those for PCA.

TLC plates under UV light for the 5.25\% NaOCl/QMix association and PCA before and after corresponding solvent development are shown in Fig. 1. The same picture is 
obtained for the other irrigant associations, indicating that none of them produces PCA as a by-product.

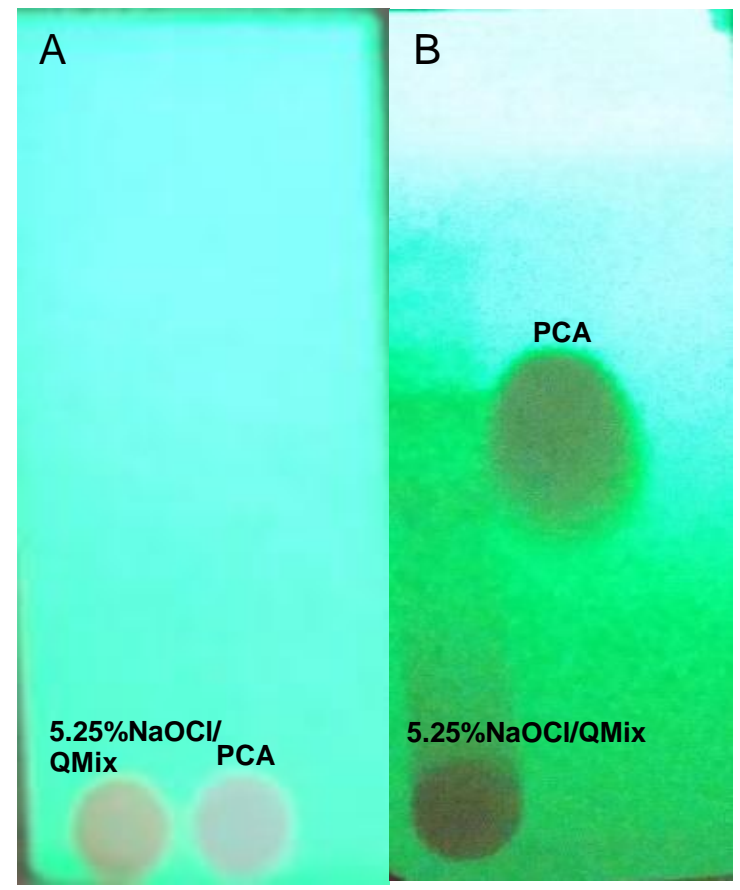

Figure 1. TLC plates under UV light for the $5.25 \% \mathrm{NaOCl} / \mathrm{QMix}$ irrigant association and PCA before $(A)$ and after $(B)$ development in solvent.

The same picture is obtained for all other investigated irrigants associations.

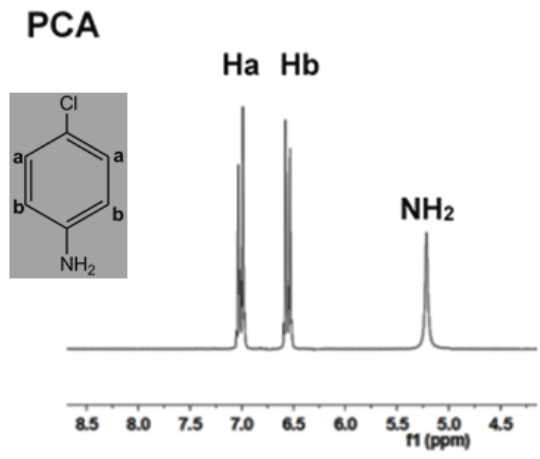

$5.25 \% \mathrm{NaOCl} / 2 \% \mathrm{CHX}$

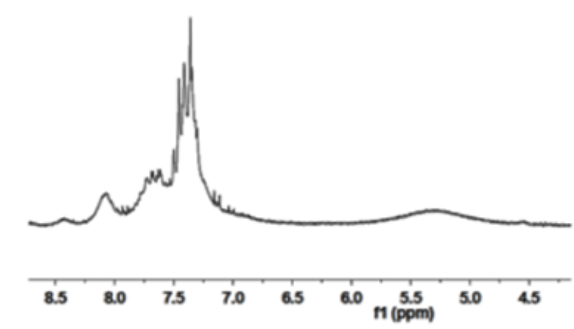

$5.25 \% \mathrm{NaOCI} / \mathrm{QMix}$

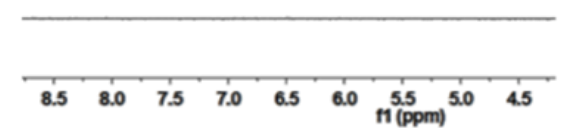

$2 \% \mathrm{CHX} / 17 \%$ EDTA

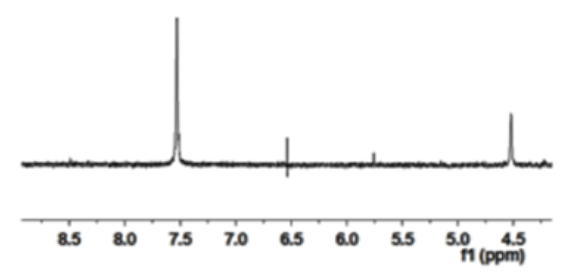

Figure 2. Analysis of investigated irrigants association products by ${ }^{1} \mathrm{H}$ NMR spectroscopy. All spectra were recorded in DMSO- $d_{6}$ at ambient temperature and compared with that obtained for PCA. 
The ${ }^{1} \mathrm{H}$ NMR spectrum for each association product was compared with the spectrum of PCA; see Fig. 2. As can be seen from this figure, two doublet signals at 7.01 and $6.56 \mathrm{ppm}$ with coupling constant $J=8.8 \mathrm{~Hz}$ are present in the spectrum of PCA and are assigned to the pairs of aromatic protons $\mathrm{H}_{\mathrm{a}}$ and $\mathrm{H}_{\mathrm{b}}$, respectively, while a singlet at $5.22 \mathrm{ppm}$ is due to the $\mathrm{NH}_{2}$ protons. However, these resonances are not present in the spectra of association products, indicating that no PCA was formed in the investigated reactions. Moreover, there was no appearance of PCA resonances characteristic in association products spectra recorded $72 \mathrm{~h}$ after their dissolution.

In the IR spectrum, PCA has two very strong and sharp bands at 3472 and $3382 \mathrm{~cm}^{-1}$, which were assigned to the asymmetric and symmetric stretching vibration of the primary amino moiety (Fig. 3). None of these bands can be detected in the spectrum of the investigated association products, additionally confirming that these products do not contain PCA.

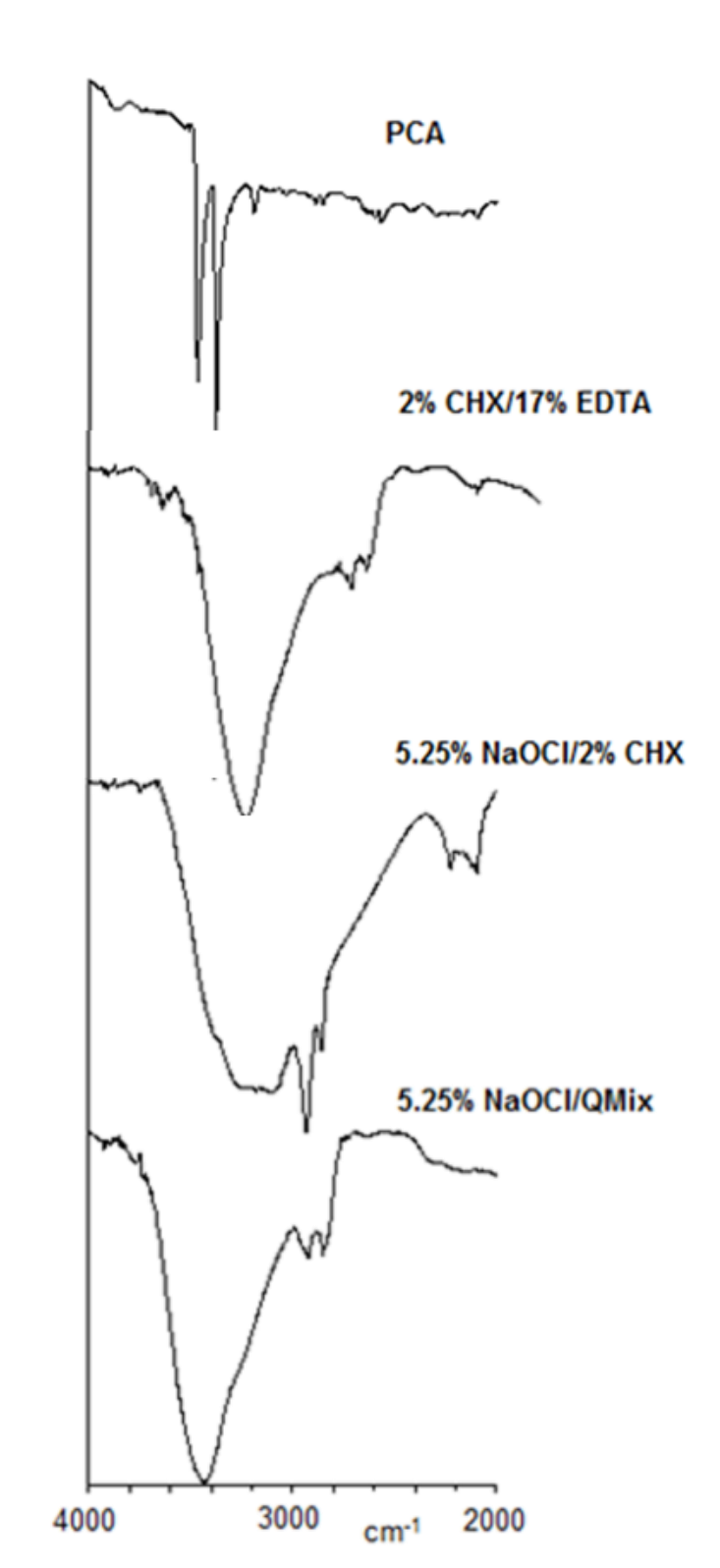

Figure 3. Analysis of the investigated irrigants association products by IR spectroscopy. Their spectra in the region of $4000-2000 \mathrm{~cm}^{-1}$ are compared with that for the PCA. 
Considering the fact that different irrigants combination during endodontic therapy may enhance their antimicrobial properties (KURUVILLA et al., 1998), possible undesirable chemical interactions among the irrigants have to be investigated (ROSSI-FEDELE et al., 2012). Some composition precipitate findings, resulted from different irrigants combination, showed that there is still a debate whether it contains PCA (TAY et al., 2006; BASRANI et al., 2007; RASIMICK et al., 2008; THOMAS et al., 2010; ARSLAN et al., 2015; ORHAN et al., 2016). Contradictory results can be explained by different detection sensitivities and methods that include handling and dissolution of the precipitate that may affect product recovery. Also, in some studies, failure to detect PCA may be related to the used materials and methods but is not an evidence of its absence (KOLOSOWSKI et al., 2014; ORHAN et al., 2016).

The purpose of this in vitro study is to determine whether PCA was formed as a byproduct of the reactions between $\mathrm{NaOCl}$ and final rinse $\mathrm{CHX}$ and QMix solutions, as well as a result of EDTA/CHX combination. This can be important because PCA is considered to be cytotoxic on human cells (WorLd HEALTH ORGANISATION, 2006), carcinogenic (ThOMAS et al., 2010) and can lead to neonates methemoglobinemia (MESSMER et al., 2015). TLC, ${ }^{1} \mathrm{H}$ NMR and IR methods were chosen for this study due to their great sensitivity in identifying components of a given reaction mixture, as well as determination of mixture purity. Moreover, ${ }^{1} \mathrm{H}$ NMR spectroscopy is one of the principal techniques used to structurally characterize compounds in a nondestructive and noninvasive manner. Previous studies (BASRANI et al., 2007; ORHAN et al., 2016) showed that the use of a destructive method, such as mass spectroscopy, which is based on breaking down of the precipitate, can lead to unreliable results. Therefore, in accordance to previous study by ORHAN et al. (2016), noninvasive spectroscopic analyses $\left({ }^{1} \mathrm{H}\right.$ NMR and IR) and TLC chromatographic method were used for the identification of compounds present in the precipitate.

On the basis of TLC, ${ }^{1} \mathrm{H}$ NMR and IR measurements, we found that a brown precipitate formed in the reaction between $5.25 \% \mathrm{NaOCl}$ and $2 \% \mathrm{CHX}$ does not contain PCA. This finding is in accordance with previous studies (KACMAR et al., 1995; SouZA et al., 2013; Prado et al., 2013), where the absence of PCA in the brown precipitate was confirmed by ${ }^{1} \mathrm{H}$ NMR and ESI-MS analysis. Moreover, NOwICKI et al. (2011), reported that $\mathrm{NaOCl} / \mathrm{CHX}$ association did not produce PCA at any measurable quantity and identified two major CHX breakdown products in $\mathrm{NaOCl}$ presence, namely $p$-chlorophenylurea and $p$ chlorophenylguanidyl-1,6-diguanidyl-hexane. Contrary to this, ${ }^{1} \mathrm{H}$ NMR study by BASRANI $e t$ al. (2007) and ARSLAN et al. (2015) showed that $\mathrm{NaOCl}$ mixed with $\mathrm{CHX}$ resulted in an orange-brown solution coloration and PCA formation. It is considered that the precipitate was formed by the acid-base reaction between CHX, a dicationic acid, that donated protons and $\mathrm{NaOCl}$ that accepted protons (BASRANI et al., 2007). This resulted in insoluble precipitate formation that can stain dentin, bond to the walls of the access cavity and root canal (KRISBNAMURTBY et al., 2010). Thus, the precipitate acts as a residual film and chemical smear layer that may compromise intracanal medicaments diffusion, disrupts canal filling adhesion and favours coronal restoration breakdown (BUI et al., 2008; PRADO et al., 2013).

Similarly, in the presence of EDTA, no decomposition of CHX to PCA was observed by TLC and spectroscopic analysis (Fig. 1-3). This is in accordance with the previous HPLC study on the CHX/EDTA association product (RASIMICK et al., 2008), showing that CHX was not decomposed by EDTA and that white product obtained from this reaction represented a salt formed by neutralization of the cationic $\mathrm{CHX}$ by the anionic EDTA, according to the equation:

$$
3 \mathrm{H}_{2} \mathrm{CHX}^{2+}(a q)+2 \operatorname{HEDTA}^{3-}(a q) \rightleftharpoons\left(\mathrm{H}_{2} \mathrm{CHX}\right)_{3}(\operatorname{HEDTA})_{2}(s)
$$


As a result of this interaction, the effect of EDTA on smear layer is reduced, therefore manufacturer's recommendation regarding the use of a root canal saline rinse after $\mathrm{NaOCl}$ and before EDTA final rinse should be adopted (RASIMICK et al., 2008).

QMix is a novel final irrigation compound containing CHX, EDTA and the detergent (DAL et al. 2011; WANG et al. 2012). Our analysis showed that 5.25\% NaOCl with QMix combination resulted in orange-brown solution coloration and bubble formation. Analogous to its constituents, QMix does not undergo decomposition to PCA in the presence of $5.25 \%$ $\mathrm{NaOCl}$, what is in accordance with the previous finding (ARSLAN et al., 2015). As can be seen from the ${ }^{1} \mathrm{H}$ NMR spectrum of the $5.25 \% \mathrm{NaOCl} / \mathrm{QMix}$ association product, none of the signals in 4.50-8.50 ppm region including those of $\mathrm{CHX}$ was detected (Fig. 2). This might have been due to the fact that CHX concentration in QMix is very low, and therefore could not be detected (ARSLAN et al., 2015). Similar results were found by KOLOSOWSKI et al. (2014), who showed that the precipitate or PCA were not produced by a mixture of $\mathrm{NaOCl}$ and QMix using Time-of-Flight Secondary Ion Mass Spectrometry (TOF-SIMS) analysis. It could be argued that the inability to identify PCA was related to the use of different detection techniques, with a reduced sensitivity to low-molecular-weight products or the use of solvents that may have undermined PCA detection (KOLOSOWSKI et al., 2014; ORHAN et al., 2016).

\section{CONCLUSIONS}

The results of our study showed no presence of $p$-chloroaniline as by-product for the none of the investigated irrigants associations, namely $5.25 \% \mathrm{NaOCl} / 2 \% \mathrm{CHX}, 2 \%$ $\mathrm{CHX} / 17 \%$ EDTA and 5.25\% NaOCl/QMix. The applied proton NMR and IR spectoscopic techinques and TLC chromatography are shown as very efficient methods of determination whether $p$-chloroaniline is formed in the reactions between presently investigated endodontic irrigants. However, further studies are needed in order to investigate chemical composition of the precipitates formed after previously mentioned associations. Study aimed in this achievement is in progress.

\section{Acknowledgments}

This study has been supported by Junior project (No: 2016/06), Faculty of Medical Sciences, University of Kragujevac, Serbia and Project supported by Ministry of Education, Science and Technological Development (Nos: 175071 and 172036), Serbia.

\section{References:}

[1] Arslan, H., Uygun, A.D., Keskin, A., Karatas, E., Seckin, F., Yildirim, A. (2015): Evaluation of orange-brown precipitate formed in root canals after irrigation with chlorhexidine and QMix and spectroscopic analysis of precipitates produces by a mixture of chlorhexidine/ $\mathrm{NaOCl}$ and QMix/ $\mathrm{NaOCl}$. International Endodontic Journal 48: 1199-1203. doi: 10.1111/iej.12427

[2] Basrani, B.R, ManeK, S., Mathers, D., Fillery, E., Sodhi, R.N. (2010): Determination of 4 chloroaniline and its derivatives formed in the interaction of sodium hypochlorite and chlorhexidine by using gas chromatography. Journal of Endodontics 36 (2): 312-314. doi: 10.1016/j.joen.2009.10.031 
[3] Basrani, B.R., ManeK, S., Sodhi, R.N.S., Fillery, E., Manzur, A. (2007): Interaction between sodium hypochlorite and chlorhexidine gluconate. Journal of Endodontics 33: 966-969. doi: 10.1016/j.joen.2007.04.001

[4] Bitter, K., Hambarayan, A., Neumann, K., Blunck, U., Sterzenbach, G. (2013): Various irrigation protocols for final rinse to improve bond strengths of fiber posts inside the root canal. European Journal of Oral Sciences 121: 349-354. doi: 10.1111/eos.12057

[5] Bui, T.B., Baumgartner, J.C., Mitchell, J.C. (2008): Evaluation of the interaction between sodium hypochlorite and chlorhexidine gluconate and its effect on root dentin. Journal of Endodontics 34: 181-185. doi: 10.1016/j.joen.2007.11.006

[6] Chhabra, R.S., Huff, J.E., Haseman, J.K., Elwell, M.R., Peters, A.C. (1991): Carcinogenicity of $p$-chloroaniline in rats and mice. Food and Chemical Toxicology 29: 119-124. doi.org/10.1016/0278-6915(91)90166-5

[7] Dai, L., Khechen, K., Khan, S., Gillen, B., Loushine, B.A., Wimmer, C.E., Gutmann, J.L., PAShley, D., TAY, F.R. (2011): The effect of QMix, an experimental antibacterial root canal irrigant, on removal of canal wall smear layer and debris. Journal of Endodontics 37: 80-84. doi: 10.1016/j.joen.2010.10.004

[8] HaApasalo, M., Shen, Y., Wang, Z., GaO, Y. (2014): Irrigation in endodontics. British dental journal 216: 299-303. doi: 10.1038/sj.bdj.2014.204

[9] HÜlsmann, M., Rödig, T., NordmeYer, S. (2007): Complications during root canal irrigation. Endodontic topics 16: 27-63. doi.org/10.1111/j.1601-1546.2009.00237.x.

[10] Gu, X.H., MaO, C.Y., Liang, C., WAng, H.M., KeRn, M. (2009): Does endodontic post space irrigation affect smear layer removal and bonding effectiveness? European Journal of Oral Sciences 117: 597-603. doi: 10.1111/j.1600-0722.2009.00661.x.

[11] Kacmar, P., Pistl, J., Mikula, I. (1995): The efect of $p$-chloroaniline on leucocytes of cheep peripheral blood under the migration-inhibition test conditions. Immunopharmacology and Immunotoxicology 17 (3): 577-584. doi: 10.3109/08923979 509016388

[12] Kolosowski, K.P., Sodhi, R.N., Kishen, A., Basrani, B.R. (2014): Qualitative analysis of precipitate formation on the surface and in the tubules of dentin irrigated with sodium hypochlorite and final rinse of chlorhexidine or QMix. Journal of Endodontics 40: 36-40. doi: 10.1016/j.joen.2014.08.017

[13] Krisbnamurtby, S., Sudbakaran, S. (2010): Evaluation and prevention of the precipitate formed on interaction between sodium hypochlorite and chlorhexidine. Journal of Endodontics 36: 1154-1157. doi: 10.1016/j.joen.2010.01.012

[14] KuRUVILla, J.R., KAMATH, M.P. (1998): Antimicrobial activity of 2.5\% sodium hypochlorite and $0.2 \%$ chlorhexidine gluconate separately and combined, as endodontic irrigants. Journal of Endodontics 24 (7): 472-476. doi: 10.1016/S00992399(98)80049-6

[15] Messmer, A., Nickel, C.H., BAREISS, D. (2015): p-Chloroaniline poisoning causing methemoglobinemia: a case report and review of the literature. Case Reports in Emergency Medicine 2015: Article ID 208732, 4 pages. doi: 10.1155/2015/208732

[16] NowICKI, J.B., SEM, D.S. (2011): An in vitro spectroscopic analysis to determine the chemical composition of the precipitate formed by mixing sodium hypochlorite and chlorhexidine. Journal of Endodontics 37: 983-988. doi: 10.1016/j.joen.2011.03.033 
[17] Orhan, E.O., IrmaK, O., HÜr, D., Yaman, B.C., KarabuCaK, B. (2016): Does parachloroaniline really form after mixing sodium hypochlorite and chlorhexidine. Journal of Endodontics 42: 455-459. doi: 10.1016/j.joen.2015.12.024

[18] Prado, M., Santos, Júnior H.M., Rezende, C.M., Pinto, A.C., Faria, R.B., Simao, R.A., GOMES, B.P. (2013): Interactions between irrigants commonly used in endodontic practice: a chemical analysis. Journal of Endodontics 39: 505-510. doi: 10.1016/j.joen.2012.11.050

[19] Prado, M., Simao, R.A., Gomes, B.P. (2013): Evaluation of different irrigation protocols concerning the formation of chemical smear layer. Microscopy Research and Technique 76 (2): 196-200. doi: 10.1002/jemt.22153

[20] Rasimick, B.J., Nekich, M., HladeK, M., Musikant, B.L., Deutsch, A.S. (2008): Interaction between chlorhexidine digluconate and EDTA. Journal of Endodontics 34: 1521-1523. doi: 10.1016/j.joen.2008.08.039

[21] Rossi-Fedele, G., Dogramaci, E.J., Guastalli, A.R., De Figueiredo, J.A. (2012): Antagonistic interactions between sodium hypochlorite, chlorhexidine, EDTA, and citric acid. Journal of Endodontics 38: 426-431. doi: 10.1016/j.joen.2012.01.006

[22] Souza, M., Cecchin, D., Barbizam, J.V., Almeida, J.F.A., Zaia, A.A., Gomes, B.P.F.A., FERRAZ, C.C.R. (2013): Evaluation of the colour change in enamel and dentine promoted by the interaction between $2 \%$ chlorhexidine and auxiliary chemical solutions. Australian endodontic journal 39 (3): 107-111. doi/10.1111/j.17474477.2011.00311.x

[23] Stojicic, S., Shen, Y., Qian, W., Johnson, B., HaApasalo, M. (2012): Antibacterial and smear layer removal ability of a novel irrigant, QMiX. International Endodontic Journal 45: 363-371. doi: 10.1111/j.1365-2591.2011.01985.x

[24] Stojicic, S., Zivkovic, S., Qian, W., Zhang, H., HaApasalo, M. (2010): Tissue dissolution by sodium hypochlorite: effect of concentration, temperature, agitation and surfactant. Journal of Endodontics 36: 1558-1562. doi: 10.1016/j.joen.2010.06.021

[25] TAy, F.R., Hiraishi, N., Schuster, G.S., PAshley, D.H., LOUShine, R.J., Ounsi, H.F., Grandini, S., Yau, J.Y.Y., Mazzoni, A., Donnelly, A., King, N.M. (2006): Reduction in antimicrobial substantivity of MTAD after inital sodium hypochlorite irrigation. Journal of Endodontics 32: 970-975. doi: 10.1016/j.joen.2006.03.016

[26] Thomas, J.E., SEM, D.S. (2010): An in vitro spectroscopic analysis to determine whether $p$-chloroaniline is produced from mixing sodium hypochlorite and chlorhexidine. Journal of Endodontics 36: 315-317. doi: 10.1016/j.joen.2009.10.028

[27] Vivacqua-Gomes, N., Ferraz, C.C., Gomes, B.P., Zaia, A.A., TeiXeira, F.B., SOUZA-FILHO, F.J. (2002): Influence of irrigants on the coronal microleakage of laterally condensed gutta-percha root fillings. International Endodontic Journal 35: 791-795. doi: 10.1046/j.1365-2591.2002.00569.x

[28] WANG, Z., SHEN, Y., HAAPASAlO, M. (2012): Effectiveness of endodontic disinfecting solutions against young and old enterococcus faecalis biofilms in dentine canals. Journal of Endodontics 38: 1376-1379. doi: 10.1016/j.joen.2012.06.035

[29] World HeAlth ORganisation (2006): IARC monography on the evaluation of carcigoneic risks to human. International Agency for Research on cancer, Lyon, France, 86: 1-25. 
[30] Zehnder, M., Schmidlin, P., Sener, B., Waltimo, T. (2005): Chelation in root canal therapy reconsidered. Journal of Endodontics 31: 817-820. doi: 10.1097/01.don.00001 58233.59316.fe 